\title{
molecules
}

ISSN 1420-3049

www.mdpi.com/journal/molecules

Article

\section{Development and Characterization of Polymorphic Microsatellite Markers (SSRs) for an Endemic Plant, Pseudolarix amabilis (Nelson) Rehd. (Pinaceae)}

\section{Qi-Fang Geng ${ }^{1,2, \dagger}$, Jun Liu ${ }^{1,2, \dagger}$, Lin Sun ${ }^{1,2}$, Hong Liu ${ }^{3,4}$, Yan Ou-Yang ${ }^{1,2}$, Ying Cai ${ }^{1,2}$, Xin-Sheng Tang ${ }^{5}$, Hong-Wei Zhang ${ }^{6}$, Zhong-Sheng Wang ${ }^{1,2, *}$ and Shu-Qing An ${ }^{1,2, *}$}

1 School of Life Science, Nanjing University, Nanjing 210093, China;

E-Mails: gengqifang@126.com (Q.-F.G.); liujun.mc@163.com (J.L.);

1988bingshan@126.com (L.S.); oyy0723@163.com (Y.O.-Y.); caiying79@126.com (Y.C.)

2 State Key Laboratory of Pharmaceutical Biotechnology, School of Life Science,

Nanjing University, Nanjing 210093, China

3 International Center for Tropical Botany, Department of Earth and Environment, Florida International University, Miami, FL 33199, USA; E-Mail: hliu@fiu.edu

4 College of Forestry, Guangxi University, Nanning 530004, China

5 College of Life and Environment Sciences, Huangshan University, Huangshan 245041, China;

E-Mail: xstang@hsu.edu.cn

6 Administration of Zhejiang Qingliangfeng National Nature Reserve, Lin'an 311321, China;

E-Mail: laqlf@163.com

$\dagger$ These authors are equally contributed to this work.

* Authors to whom correspondence should be addressed; E-Mails: wangzs@nju.edu.cn (Z.-S.W.); anshq@nju.edu.cn (S.-Q.A.); Tel.: +86-25-8968-2705 (Z.-S.W.); +86-25-8968-4560 (S.-Q.A.).

Academic Editor: Derek J. McPhee

Received: 14 January 2015 / Accepted: 29 January 2015 / Published: 4 February 2015

\begin{abstract}
Pseudolarix (Pinaceae) is a vulnerable (sensu IUCN) monotypic genus restricted to southeastern China. To better understand levels of genetic diversity, population structure and gene flow among populations of $P$. amabilis, we developed five compound SSR markers and ten novel polymorphic expressed sequence tags (EST) derived microsatellites. The results showed that all 15 loci were polymorphic with the number of alleles per locus ranging from two to seven. The expected and observed heterozygosities varied from 0.169 to 0.752 , and 0.000 to 1.000 , respectively. The inbreeding coefficient ranged from -0.833 to 1.000 .
\end{abstract}


These markers will contribute to research on genetic diversity and population genetic structure of $P$. amabilis, which in turn will contribute to the species conservation.

Keywords: microsatellite markers; ESTs; SSRs; Pseudolarix amabilis; Pinaceae

\section{Introduction}

Pseudolarix is a monotypic genus in the family Pinaceae. The fossil record of Pseudolarix reveals wide distribution in North America and Eurasia during the Early Cretaceous (Berriasian), possibly the Late Jurassic (Portlandian) and the Plio-Pleistocene [1]. The only species of this genus, Pseudolarix amabilis is threatened, and it is restricted to hills and alluvial plains, commonly below $1000 \mathrm{~m}$ in elevation, along the lower Yangtze River valley in southeast China [1]. Its primary habitat is highly fragmented and degraded because of intense and relatively recent human activities [2]. This Chinese endemic species is listed as vulnerable based on the IUCN criteria [2,3]. Comprehensive knowledge on genetic diversity and population structure of natural populations is essential for species management and conservation, as it reflects the status and survival potential of populations. Several studies have focused on the various aspects of the biology of $P$. amabilis [4-10], including a population genetic study [11]. However, the existing population genetics study of $P$. amabilis was based on dominant molecular markers (i.e., RAPDS) and was limited to nine populations from the coastal province of Zhejiang.

In recent years, microsatellites or Simple Sequence Repeats (SSRs) have been widely used in studies of population genetics because of their abundance, high level of polymorphism, co-dominance, bi-parentally inheritance, and easy detection by polymerase chain reaction (PCR) [12-14]. In general, SSRs are divided in two categories: (1) genomic SSRs developed from random genomic sequences and (2) EST-derived SSR markers (EST-SSRs) derived from expressed sequences tags in public sequence database [15]. An improved genomic SSR technique, i.e., isolation of codominant compound SSR markers from genomic DNA, has been recently developed and applied to population genetics studies in both plant and animal species [13,16-18]. In this approach, a locus-specific primer is designed from the sequence flanking the compound SSR, and the primer pairs of the locus-specific and compound SSR primers were used as a compound SSR marker. This approach sidesteps the second step of the dual-suppression-PCR method and enable substantial time and cost savings [19,20].

In this study, we developed both compound SSR markers and EST-derived SSR markers from $P$. amabilis in order to assess its genetic diversity, population genetic structure throughout its distribution, which will likely have important implications for its conservation and management strategies.

\section{Results and Discussion}

For the compound SSR markers, a total of 300 positive clones were chosen and tested. We randomly chose 95 fragments to sequence, of which 86 were successfully sequenced, six had the same sequence. All successfully sequenced fragments were flanked by a compound SSR sequence at one end. In total, 69 fragments that contained $(\mathrm{AC})_{6}(\mathrm{TC})_{\mathrm{n}}(1),(\mathrm{TC})_{6}(\mathrm{AC})_{\mathrm{n}}(25),(\mathrm{AC})_{6}(\mathrm{AG})_{\mathrm{n}}(21)$, or $(\mathrm{TC})_{6}(\mathrm{TG})_{\mathrm{n}}(22)$ repeats at one end were used to design the IP1 primers. Of 69 compound microsatellite loci isolated from 
P. amabilis, 30 loci were successfully amplified and yielded a single PCR product each. Five of these loci were polymorphic in the initial pilot studies with one population.

Among the 118 EST-SSRs, 27 (22.9\%) were dinucleotide repeats, and 91 (77.1\%) were trinucleotides. The most common dinucleotide and trinucleotide repeats were motifs (AT) $\mathrm{n}(13.8 \%)$ and (TAC) $\mathrm{n}(9.3 \%)$. The motifs $(\mathrm{AT}) \mathrm{n},(\mathrm{AC})_{\mathrm{n}},(\mathrm{AG})_{\mathrm{n}}(\mathrm{TC})_{\mathrm{n}}$ and $(\mathrm{GT})_{\mathrm{n}}$ accounted for $22.9 \%$ of the 118 random selected EST-derived SSR markers. Thirty five of the primer pairs (29.7\%) amplified the expected products. Of the 35 amplified loci, ten (8.5\%) loci were polymorphic in the test population.

Details pertinent to PCR amplification features and genetic diversity parameters for these 15 polymorphic microsatellite loci are presented in Table 1. There were two to seven alleles per locus (Table 1). The expected $\left(H_{\mathrm{E}}\right)$ and observed $\left(H_{\mathrm{O}}\right)$ heterozygosities ranged from 0.169 to 0.752 , and from 0.000 to 1.000 , respectively (Table 1$)$. The inbreeding coefficient $\left(F_{\text {IS }}\right)$ ranged from -0.833 to 1.000 . Seven loci deviated significantly from Hardy Weinberg Equilibrium $(p<0.001)$ (Table 1), because of an excess of homozygotes. Null alleles, inbreeding, Wahlund effect, and small population size might lead to the excess of homozygotes. Because it is usually difficult to avoid null alleles, we recommend that the future population genetic studies of $P$. amabilis correct the genotype data from these 15 microsatellite loci by software (e.g., MICRO-CHECKER [21]). Moreover, the effects of sample and habitat size also should be determined in the population genetic studies. Among the 15 microsatellite loci, significant linkage disequilibrium was detected between PA67 and PA89 $(p<0.001)$. With the compound SSR and EST-SSR markers developed in our study, further studies can be conducted. These SSR markers should be useful to investigate the genetic diversity, population genetic structure, and gene flow of P. amabilis.

\section{Experimental Section}

\subsection{Plant Materials and DNA Extraction}

A total of 24 individuals of $P$. amabilis were collected from a single population located in Changxing County, Huzhou, China $\left(31^{\circ} 7^{\prime} 28^{\prime \prime} \mathrm{N}, 119^{\circ} 45^{\prime} 22^{\prime \prime} \mathrm{E}\right)$. Leaves were randomly sampled from trees at an interval of at least $10 \mathrm{~m}$ and immediately put into the plastic sealed bag with silica gel for fast drying, and then stored at room temperature until use. Total genomic DNA of $P$. amabilis was extracted from dried leaves using a modified Cetytrimethyl Ammonium Bromide (CTAB) method with minor modifications [22]. The DNA was dissolved in $200 \mu \mathrm{L}$ of sterilized water and kept at $-30{ }^{\circ} \mathrm{C}$ until use. Two methods were employed to isolate SSR markers for $P$. amabilis, a technique for isolating codominant compound SSR markers, and expressed sequence tag (EST)-derived SSR markers.

\subsection{Compound SSR Markers}

Genomic DNA of $P$. amabilis was extracted from dried leaves and then was separately digested with six blunt-end restriction enzymes, i.e., RsaI, AluI, EcoRV, HaeIII, HincII and SspI. The restriction fragments were then ligated with a specific blunt adaptor (consisting of the 48-mer: 5'-GTAATACGACTCACTATAGGGCACGCGTGGTCGACGGCCCGGGCTGGT-3' and an 8-mer with the 3'-end capped with an amino residue: 5'-ACCAGCCC-NH $2-3$ ') using the Takara DNA ligation kit. 
Table 1. Characteristics of 15 microsatellite markers isolated from Pseudolarix amabilis.

\begin{tabular}{|c|c|c|c|c|c|c|c|c|c|c|}
\hline Locus & Primer Sequence (5'-3') & Modif & GenBank Accession No. & $\boldsymbol{T}_{\mathrm{a}}\left({ }^{\circ} \mathbf{C}\right)$ & $\begin{array}{c}\text { No. of } \\
\text { Samples }\end{array}$ & $\begin{array}{l}\text { Size Range } \\
\text { (bp) }\end{array}$ & $\begin{array}{l}\text { No. of } \\
\text { Alleles }\end{array}$ & $H_{\mathrm{O}}$ & $\boldsymbol{H}_{\mathbf{E}}$ & $F_{\text {IS }}$ \\
\hline Psam05 & $\begin{array}{l}\text { R: CTAGTGCATCGGGTTGCTAAA } \\
\text { F: ACACACACACACACAGAGAG }\end{array}$ & $(\mathrm{AC})_{6}(\mathrm{AG})_{22}$ & KP418960 & 54 & 24 & $139-147$ & 4 & 0.417 & 0.600 & 0.325 \\
\hline Psam06 & $\begin{array}{l}\text { R: GGATTGTAGTCATTGGAGTTAGAG } \\
\text { F: ACACACACACACACAGAGAG }\end{array}$ & $(\mathrm{AC})_{6}(\mathrm{AG})_{5} \ldots(\mathrm{TC})_{20}$ & KP418961 & 53 & 24 & $226-232$ & 4 & 0.579 & 0.680 & 0.175 \\
\hline Psam09 * & $\begin{array}{l}\text { F: CCAAGGTCTGATGTAGATTGCTTG } \\
\text { F: ACACACACACACACAGAGAG }\end{array}$ & $(\mathrm{AC})_{6}(\mathrm{AG})_{20}$ & KP418962 & 58 & 24 & $140-148$ & 5 & 0.917 & 0.675 & -0.339 \\
\hline Psam44 * & $\begin{array}{l}\text { R: CGTCAATGATCCATAATGGCTACA } \\
\text { F: ACACACACACACACAGAGAG }\end{array}$ & $(\mathrm{AC})_{6}(\mathrm{AG})_{30}$ & KP418963 & 56 & 24 & $294-306$ & 7 & 0.391 & 0.752 & 0.497 \\
\hline Psam $45 *$ & $\begin{array}{l}\text { R: TACAATCTCAAGTAGGTCCGTAT } \\
\text { F: ACACACACACACACAGAGAG }\end{array}$ & $(\mathrm{AC})_{6}(\mathrm{AG})_{25}$ & KP418964 & 55 & 24 & $169-183$ & 5 & 0.042 & 0.445 & 0.910 \\
\hline PA09 & $\begin{array}{l}\text { F: U19-CGTAGTATGAGGACCACAGTT } \\
\text { R: TTCTGCATCCTACAAGGTTT }\end{array}$ & $(\mathrm{GAA}) 9$ & SRR290437.4323.2 & 55 & 24 & $161-167$ & 3 & 0.333 & 0.500 & 0.412 \\
\hline PA25 & $\begin{array}{l}\text { F: U19-AATGGGCATTGAACTTCTTA } \\
\text { R: GACGCGACCACACCTAT }\end{array}$ & $(\mathrm{AC})_{19}$ & SRR290437.17687.2 & 54 & 24 & $245-247$ & 2 & 0.000 & 0.320 & 1.000 \\
\hline PA51 & $\begin{array}{l}\text { F: U19-CAAATACAATTACGCCTTCG } \\
\text { R: GTCCACTGTCCAACTTTGTT }\end{array}$ & $(\mathrm{AT})_{11}$ & SRR290437.68993.2 & 55 & 24 & $138-140$ & 2 & 0.000 & 0.408 & 1.000 \\
\hline PA60 * & $\begin{array}{l}\text { F: U19-AAGATCATGGAGAATTGCTG } \\
\text { R:AGCTTGAGGTCACGATAGAA }\end{array}$ & $(\mathrm{AAG})_{12}$ & SRR290437.29511.2 & 56 & 24 & $191-195$ & 3 & 0.000 & 0.169 & 1.000 \\
\hline PA67 & $\begin{array}{l}\text { F: U19-AAACATGATGGAGGAATACG } \\
\text { R:TTGAAGGAAACAGAAACAGC }\end{array}$ & $(\mathrm{TCT})_{7}$ & SRR290437.39562.2 & 56 & 24 & $132-135$ & 3 & 0.045 & 0.208 & 0.790 \\
\hline PA78* & $\begin{array}{l}\text { F:U19-ATGGAAGGAGGATGGTAAAT } \\
\text { R:AAACTCTTCCATGAGAGCAA }\end{array}$ & $(\mathrm{GAG})_{8}$ & SRR290437.49150.2 & 56 & 24 & $263-275$ & 6 & 1.000 & 0.650 & -0.520 \\
\hline PA84 & $\begin{array}{l}\text { F: U19-ACCATTCTATCGTTTCTCCA } \\
\text { R:GCCACATGAGCAGAAGACTA }\end{array}$ & $(\mathrm{GCA})_{8}$ & SRR290437.51696.2 & 56 & 24 & $225-239$ & 3 & 0.158 & 0.314 & 0.518 \\
\hline PA89 * & $\begin{array}{l}\text { F: U19-TATTGCTAGAAGAGGGCAAG } \\
\text { R:CTTGTAGTAGGTGCGGAATC }\end{array}$ & $(\mathrm{TTC})_{8}$ & SRR290437.57471.2 & 56 & 24 & $299-307$ & 3 & 0.042 & 0.414 & 0.903 \\
\hline PA93 & $\begin{array}{l}\text { F: U19-CATCCCGTTCTTGATCTTAC } \\
\text { R:GAAACTTAGGGTTTGGAAGG }\end{array}$ & $(\mathrm{CTG})_{8}$ & SRR290437.62539.2 & 56 & 24 & $275-284$ & 2 & 0.158 & 0.494 & 0.695 \\
\hline PA107* & $\begin{array}{l}\text { F: U19-TCTCCGGCACTAGTAGACAT } \\
\text { R:TGGTCAGTTTGATGAGAACA }\end{array}$ & $(\mathrm{CAG})_{7}$ & SRR290437.67270.2 & 56 & 24 & $198-205$ & 4 & 1.000 & 0.543 & -0.833 \\
\hline
\end{tabular}


Fragments flanked by an SSR region at one end were amplified by PCR from the EcoRV and SspI DNA library using a compound SSR primer (AC)6(TC)5, (TC)6(AC)5, (AC)6(AG)5, (AG)6(AC)5 or (TC) 6 (TG) 5 and an adaptor primer (5'-CTATAGGGCACGCGTGGT-3'). The amplified fragments were cloned into Trans ${ }^{\mathrm{TM}} p E A S Y$-T1 Cloning vector system (Transgen, Beijing, China). Transformants were identified by blue/white screening on LB agar plates containing Ampicillin, X-gal and IPTG. The cloned fragments were amplified using the M13 forward and reverse primers from the plasmid DNA of positive clones. The plasmid DNA of the fragments (from 400 to $550 \mathrm{bp}$ ) were sequenced using M13 primer by Invitrogen. For each fragment containing an $(\mathrm{AC})_{6}(\mathrm{TC})_{n},(\mathrm{TC})_{6}(\mathrm{AC})_{n},(\mathrm{AC})_{6}(\mathrm{AG})_{n}$, $(\mathrm{AG})_{6}(\mathrm{AC})_{n}$ or $(\mathrm{TC})_{6}(\mathrm{TG})_{n}$ compound SSR sequence at one end, a locus-specific primer (IP1) was designed from the region flanking the compound SSR sequence. The IP1 and corresponding compound SSR primers were used as a compound SSR marker.

\subsection{Expressed Sequence Tag (EST) SSR Markers}

Transcriptome sequences of $P$. amabilis were downloaded from the Short Read Archive (SRA) of the National Center for Biotechnology Information (NCBI) with accession numbers of SRR290437 (http://www.ncbi.nlm.nih.gov/sra/?term=pseudolarix+amabilis). A total of 733,434 unigenes with a total length of $855.4 \mathrm{Mb}$ were obtained. The obtained unigenes were then analyzed using the SciRoKo v3.4 software [23] to identify reads containing simple tandem repeats. We used the Mismatched; Fixed Penalty mode with a mismatch penalty of five to identify microsatellites. At least 10 repeats for dinucleotide motifs and six repeats for trinucleotide motifs were selected for further study. We designed the primers using PRIMER 3 software [24] with the following parameters, a $40 \%-60 \%$ GC content, 100-300 bp final product size, primer $\mathrm{T}_{\mathrm{ms}}$ of $52-58^{\circ} \mathrm{C}$ (optimum $55^{\circ} \mathrm{C}$ ) and a $3{ }^{\circ} \mathrm{C}$ maximum difference in melting temperature between paired primers. Primers were successfully designed for 12,141 of these microsatellite-contained sequences. We randomly selected 118 of the 12,141 primer pairs for PCR validation.

\subsection{Polymorphism Detection}

PCR amplification was carried out with a reaction mixture $(10 \mu \mathrm{L})$, containing about $10 \mathrm{ng}$ of template DNA, 1× AmpliTaq Gold 360 Master Mix (Applied Biosystems, Carlsbad, CA, USA), 4\% of 360 GC Enhancer (Applied Biosystems) and $0.5 \mu \mathrm{M}$ of each designed primer.

For the loci isolated by the compound SSR method, the corresponding markers (i.e., (AC)7(TC) 3 ,

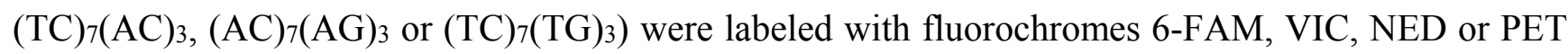
(Applied Biosystems).

For the EST-derived SSR markers, we used a tailed primer method to perform PCR, a U19 (5'-GGTTTTCCCAGTCACGACG-3', [25]) was tailed to the 5' end of the forward primer, and the U19 primer labeled with 6-FAM, VIC, NED or PET, was added to the PCR reaction mix.

The PCR reactions were conducted on a Veriti Thermal Cycler (Applied Biosystems). The PCR reaction was performed using the following cycling conditions: denaturation at $95{ }^{\circ} \mathrm{C}$ for $10 \mathrm{~min}$; followed by 38 cycles of $30 \mathrm{~s}$ at $95{ }^{\circ} \mathrm{C}, 30 \mathrm{~s}$ at annealing temperature of primer pair and $1 \mathrm{~min}$ at $72{ }^{\circ} \mathrm{C}$; then final extension at $72{ }^{\circ} \mathrm{C}$ for $7 \mathrm{~min}$. PCR products were analyzed using an ABI 3730 genetic analyzer (Applied Biosystems). Alleles sizes were determined using the GeneMapper ${ }^{\mathrm{TM}}$ analysis software version 4.0 (Applied Biosystems) according to a LIZ-500 DNA size standard (Applied Biosystems). 


\subsection{Data Analysis}

Number of alleles per locus $\left(N_{\mathrm{A}}\right)$, observed heterozygosity $\left(H_{\mathrm{O}}\right)$, and expected heterozygosity $\left(H_{\mathrm{E}}\right)$ were assessed using GENALEX 6.5 [26,27]. Hardy-Weinberg equilibrium (HWE) and linkage disequilibrium between pairs of microsatellites were calculated with Genepop 4.2 [28,29]. The inbreeding coefficient $\left(F_{\mathrm{IS}}\right)$ was calculated by FSTAT version 2.9.3 [28].

\section{Conclusions}

We successfully developed and characterized SSR markers derived from the expressed sequence tags as well as codominant compound SSRs isolated from genomic DNA of P. amabilis. With these fifteen polymorphic SSR markers, further population genetic studies of $P$. amabilis can be carried out for the species' conservation and management.

\section{Acknowledgments}

This work was supported by the National Natural Science Foundation of China (Grants No. 31100270). We thank Javier Francisco Ortega of Florida International University for his kind comments and suggestions on this manuscript. We would like to thank Weixiang $\mathrm{Xu}$, Bin Cheng, Qinhua Gong, Dongliang Yang and Chunhui Hu for their kind assistance in collecting samples. We are grateful to Jingtao Sun of Nanjing Agricultural University for his kind technical assistance.

\section{Author Contributions}

Qifang Geng, Zhongsheng Wang and Shuqing An conceived and designed the experiments; Qifang Geng wrote the manuscript; Hong Liu edited the manuscript; Jun Liu, Lin Sun, Yan Ouyang, Ying Cai, Xinsheng Tang, and Hongwei Zhang performed the experiments. All authors read and approved the manuscript.

\section{Conflicts of Interest}

The authors declare no conflict of interest.

\section{References}

1. Lepage, B.A.; Basinger, J.F. Evolutionary history of the genus Pseudolarix gordon (Pinaceae). Int. J. Plant Sci. 1995, 156, 910-950.

2. Fang, Y.P.; Hu, Z.X.; Xiang, J.; Hu, Y. Resource and protection of the national key preserved wild plants in Dabieshan, eastern of Hubei. Ecol. Sci. 2006, 25, 312-315.

3. Fu, L.G.; Jin, J.M. China Plant Red Data Book: Rare and Endangered Plants; Science Press: Beijing, China, 1992; Volume 1, pp. 110-111.

4. Shao, L.X.; Zhang, F.J. Sem observation on leaf epidermis of 6 species in Pinaceae. Chin. Bull. Bot. 2005, 25, 281-285.

5. Yu, F.Y.; Qian, J. A seed quality study of Pseudolarix amabilis in different collection periods. J. Cent. South For. Univ. 1999, 19, 45-47. 
6. Qian, H.T.; Zhang, J.L.; Song, J.F.; Zhang, T.; Yan, J.F.; Shi, J.M. The effect on growth of Pseudolarix amabilis by seedling transplant measures. China For. Sci. Technol. 2005, 19, 59-60.

7. Wang, L.Y.; Yang, Y.C.; Song, Y.B. Dynamic study on growth of man-made Pseudolarix kaempferi forests in Tiantong National Forest Park. J. Zhejiang For. Sci. Technol. 2005, 25, 5-9.

8. Liu, H.L.; He, C.Z. Research status and prospect of the chemical constituents and bioactivities of Pseudolarix kameferi. J. Southwest For. Coll. 2008, 28, 52-56.

9. Li, L.C. A cytotaxonomical study on Pseudolarix kameferi. Acta Botanica Yunanica 1994, 16, $248-254$.

10. Wu, W.S.; Zhang, Q.Q.; Liu, J.Q. Karyotype studies of Pseudolarix amabilis. J. Fujian Teachers Univ. (Nat. Sci.) 1996, 12, 81-83.

11. Gao, Y.H.; Fan, M.L.; Luo, W.J.; Huang, H.H.; Tong, Z.K. RAPD analysis of genetic diversity for Pseudolarix amabilis: A critically endangered plant. J. Zhejiang A \& F Univ. 2011, 28, 815-822.

12. Aggarwal, R.K.; Lalremruata, A.; Velavan, T.P.; Sowjanya, A.P.; Singh, L. Development and characterization of ten novel microsatellite markers from olive ridley sea turtle (Lepidochelys olivacea). Conserv. Genet 2008, 9, 981-984.

13. Geng, Q.F.; Lian, C.L.; Goto, S.; Tao, J.M.; Kimura, M.; Islam, M.D.S.; Hogetsu, T. Mating system, pollen and propagule dispersal, and spatial genetic structure in a high-density population of the mangrove tree Kandelia candel. Mol. Ecol. 2008, 17, 4724-4739.

14. Sun, J.T.; Jiang, X.Y.; Wang, M.M.; Hong, X.Y. Development of microsatellite markers for, and a preliminary population genetic analysis of, the white-backed planthopper. Bull Entomol. Res. 2014, 104, 765-773.

15. Li, M.; Zhu, L.; Zhou, C.Y.; Lin, L.; Fan, Y.J.; Zhuang, Z.M. Development and Characterization of EST-SSR Markers from Scapharca broughtonii and Their Transferability in Scapharca subcrenata and Tegillarca granosa. Molecules 2012, 17, 10716-10723.

16. Inoue, T.; Kaneko, Y.; Yamazaki, K.; Anezaki, T.; Yachimori, S.; Ochiai, K.; Lin, L.K.; Pei, K.J.C.; Chen, Y.J.; Chang, S.W.; et al. Genetic population structure of the masked palm civet Paguma larvata, (Carnivora: Viverridae) in Japan, revealed from analysis of newly identified compound microsatellites. Conserv. Genet 2012, 13, 1095-1107.

17. Islam, M.S.; Lian, C.; Kameyama, N.; Hogetsu, T. Low genetic diversity and limited gene flow in a dominant mangrove tree species (Rhizophora stylosa) at its northern biogeographical limit across the chain of three Sakishima islands of the Japanese archipelago as revealed by chloroplast and nuclear SSR analysis. Plant Syst. Evol. 2014, 300, 1123-1136.

18. Sun, J.T.; Lian, C.; Navajas, M.; Hong, X.Y. Microsatellites reveal a strong subdivision of genetic structure in Chinese populations of the mite Tetranychus urticae Koch (Acari: Tetranychidae). BMC Genet. 2012, 13, doi:10.1186/1471-2156-13-8.

19. Lian, C.; Hogetsu, T. Development of microsatellite markers in black locust (Robinia pseudoacacia) using a dual-supression-PCR technique. Mol. Ecol. Notes 2002, 2, 211-213.

20. Lian, C.L.; Wadud, M.A.; Geng, Q.F.; Shimatani, K.; Hogetsu, T. An improved technique for isolating codominant compound microsatellite markers. J. Plant Res. 2006, 119, 415-417.

21. Chapuis, M.P.; Estoup, A. Microsatellite null alleles and estimation of population differentiation. Mol. Biol. Evol. 2007, 24, 621-631. 
22. Lian, C.L.; Hogetsu, T.; Matsushita, N.; Guerin-Laguette, A.; Suzuki, K.; Yamada, A. Development of microsatellite markers from an ectomycorrhizal fungus, Tricholoma matsutake, by an ISSR-suppression-PCR method. Mycorrhiza 2003, 13, 27-31.

23. Kofler, R.; Schlotterer, C.; Lelley, T. SciRoKo: A new tool for whole genome microsatellite search and investigation. Bioinformatics 2007, 23, 1683-1685.

24. Rozen, S.; Skaletsky, H. Primer3 on the WWW for general users and for biologist programmers. In Bioinformatics Methods and protocols: Methods in Molecular Biology; Misener, S., Krawetz, S., Eds.; Humana Press: Totowa, NJ, USA, 2000; pp. 365-386.

25. Geng, Q.F.; Lian, C.L.; Tao, J.M.; Qiu, R.L.; Hogetsu, T. Development of microsatellite markers in a mangrove tree species Aegiceras corniculatum (Myrsinaceae). Mol. Ecol. Notes 2006, 6, 1231-1233.

26. Peakall, R.; Smouse, P.E. GenAlEx 6.5: Genetic analysis in Excel. Population genetic software for teaching and research-An update. Bioinformatics 2012, 28, 2537-2539.

27. Peakall, R.; Smouse, P.E. GENALEX 6: Genetic analysis in Excel. Population genetic software for teaching and research. Mol. Ecol. Notes 2006, 6, 288-295.

28. Raymond, M.; Rousset, F. Genepop (Version 1.2): Population Genetics Software for Exact Tests and Ecumenicism. J. Hered 1995, 86, 248-249.

29. Rousset, F. GENEPOP'007: A complete re-implementation of the GENEPOP software for Windows and Linux. Mol. Ecol. Resour. 2008, 8, 103-106.

Sample Availability: Samples are available from the authors.

(C) 2015 by the authors; licensee MDPI, Basel, Switzerland. This article is an open access article distributed under the terms and conditions of the Creative Commons Attribution license (http://creativecommons.org/licenses/by/4.0/). 